\title{
Kesenian Wayang Pada Masa Klasik Di Jawa
}

\section{Rita Istari}

Keywords: wayang, shadow puppet, java, literature, inscription, relief, kakawin, babad

\section{How to Cite:}

Istari, R. (2003). Kesenian Wayang Pada Masa Klasik Di Jawa. Berkala Arkeologi, 23(2), 51-60. https://doi.org/10.30883/jba.v23i2.875

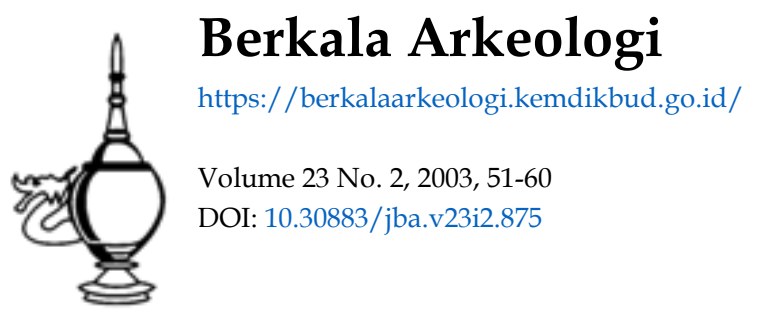

\section{c) (1)(2)}

This work is licensed under a Creative Commons Attribution-NonCommercial-ShareAlike 4.0 International License. 


\section{KESENIAN WAYANG PADA MASA KLASIK DI JAWA}

\section{T.M. Rita Istari}

\section{$\mathbf{P}$}

endahuluan

Masyarakat Indonesia, khususnya di Jawa dan Bali, pertunjukan wayang sampai sekarang masih digemari orang. Selain keseniannya, mungkin juga disebabkan karena wayang mempunyai nilai-nilai istimewa yang tersembunyi di dalamnya. Wayang adalah gambaran kehidupan di dunia yang tidak kekal, dan dianggap sebagai bayangan saja yang sifatnya maya. Wayang adalah gambaran dari sifat manusia yang bermacam-macam, di dalam lakon-lakonnya juga dijumpai nasehat-nasehat tentang bagaimana manusia harus berperilaku dalam menghadapi kehidupan di dunia fana.

Wayang merupakan hasil prestasi puncak masa lalu para leluhur yang bertempat tinggal di Pulau Jawa, dengan demikian dapat dianggap sebagai warisan budaya Indonesia yang patut dijadikan milik bersama karena isi kandungannya, baik berupa etika maupun estetikanya, tahan uji selama ber abad-abad dan tidak henti-hentinya memukau perhatian orang-orang di dalam maupun di luar negeri. Ajaran yang terkandung dalam seni budaya wayang yang tersebar paling luas itu tidak pula bertentangan dengan filsafat dasar yang mempersatukan bangsa Indonesia.

Di Indonesia terdapat puluhan jenis wayang yang tersebar di Pulau Jawa, Bali dan pulau-pulau lainnya. Sedangkan jenis-jenis wayang yang akhirnya berkembang menjadi ber macam-macam jenis tersebut, pada hakekatnya dalam pertunjukannya di masa sekarang - terutama di Jawa - masih mengacu pada pertunjukan masa lalu.

Jenis-jenis wayang tersebut antara lain:

a. Wayang Beber, yaitu wayang yang adegan-adegannya dilukiskan dalam gulungan kertas atau kain panjang. Cara memainkannya, gulungan lukisan wayang itu dibeberkan adegan demi adegan sambil dikisahkan oleh seorang dalang.

b. Wayang Golek, wayang yang dibuat dari kayu berupa sebuah boneka disebut juga boneka tiga demensi. Pertunjukan wayang ini sangat dikenal di pulau Jawa, ceritanya bersumber pada kisah Mahabharata dan Ramayana.

c. Wayang Gedhog, sejenis wayang Golek terbuat dari kayu. Wayang ini pernah terkenal di Jawa tengah dan Jawa Timur. Biasanya mengambil cerita tentang Kisah Panji.

d. Wayang Keling, wayang yang terbuat dari kulit binatang (kerbau), wayang jenis ini berkembang dengan gaya Jawa bagian wilayah pesisir utara Jawa. Dipentaskan pada saat diadakan upacara adat, isinya mengisahkan tentang silsilah raja-raja Mataram kuna. 
e. Wayang Klitik, atau disebut juga Wayang Krucil, wayang ini dibuat dari kayu, berbentuk boneka pipih seperti halnya wayang kulit.

f. Wayang Kulit atau disebut juga wayang Purwa, wayang yang dibuat dari kulit binatang. Sampai sekarang wayang jenis ini masih dikenal terutama pada masyarakat Jawa yang tentu saja sudah banyak mengalami perkembangan. Isi cerita biasanya mengisahkan tentang kebaikan dan keburukan yang termuat dalam kisah Mahabharata dan Ramayana.

g. Wayang Wong, wayang yang para pelakunya diperankan oleh manusia. Isi cerita mengambil epos Mahabharata dan Ramayana. (Marsono; 1999/2000).

Masyarakat Jawa sekarang, pada saat upacara tertentu, pertunjukan wayang masih diselenggarakan dengan lakon tertentu pula, misalnya; upacara ruwatan, bersih desa, dan sebagainya. Pada masa masuknya Islam, kesenian wayang juga digunakan sebagai alat untuk menyebarkan agama. Demikian populernya kesenian wayang hingga saat ini dalam kehidupan masyarakat kita, tetapi dalam tulisan singkat ini akan membahas sejak kapan kesenian wayang mulai dikenal oleh masyarakat Jawa, tanpa membicarakan falsafah yang terkandung di dalamnya.

\section{umber-sumber yang Memuat Tentang Wayang. \\ 1. Sumber Prasasti \\ a. Prasasti Penampihan 898 M.}

Prasasti ini dibuat pada masa pemerintahan raja Balitung sekitar tahun 820 Saka atau 898 Masehi. Pada bait 17 dikatakan: nta je ringgit inadegaken hyang marmanya sinung kmita hyang sang hyang sagdaji prasasti mata nda balitung utungga dewa ........

Artinya : ....... Diadakan pertunjukan wayang untuk para hyang...............

Jadi dimungkinkan berkaitan dengan kebiasaan manusia dalam mengadakan hubungan dengan roh-roh nenek moyang. Ketika pengaruh Hindu masuk ke Indonesia maka dewa-dewa Hindu juga menjadi pokok cerita dalam pertunjukan wayang. Dewa-dewa Hindu juga disebut Hyang maka istilah ringgit inadegaken hyang yang disebut dalam prasasti Penampihan ini dapat memperkuat pendapat tersebut.

\section{b. Prasasti Wukayana}

Prasasti ini berasal dari masa pemerintahan raja Balitung berangka tahun 829 Saka atau 907 Masehi. Pada sisi belakang dari prasasti ini dijumpai kalimat sebagai berikut si galigi mawayang buat hyang macarita bimma ya kumara......

Artinya : .... seseorang yang bernama Galigi yang berperan sebagai dalang memainkan wayang untuk penghormatan kepada para hyang dengan mengambil cerita Bimma Kumara........ 


\section{c. Prasasti yang terdiri atas empat lempengan tembaga}

Prasasti ini dari desa Bejijong yang terletak di Kecamatan Trowulan, Kabupaten Mojokerto. Prasasti ini kira-kira berasal dari abad IX Masehi. Setelah dibaca diketahui bahwa lempengan tersebut merupakan prasasti yang dikeluarkan oleh raja Sindok pada tahun 861 Saka, untuk meresmikan tanah Alasantan menjadi Sima/daerah perdikan. Mulai dari lempengan ke empat baris 17, disebutkan tentang pesta-pesta yang diadakan pada akhir upacara peresmian sima. Pada baris 19 dapat dijumpai kalimat sebagai berikut;

$i$ tlas=ning manonton men men mulih sira kabaih irikan wngi mananggap tang rakryan wayang mangaran si kapulungan winaih ma 2 wdihan hlai 1

Diartikan kurang lebih sebagai berikut:

menanggap wayang dengan dalang yang bernama si Kapulungan.

\section{d. Prasasti-prasasti lain}

Prasasti-prasasti lain yang menyebutkan tentang wayang tetapi dalam arti lain misalnya prasasti Cane (943 Saka), prasasti Patakan dari jaman pemerintahan Airlangga yang menyebutkan istilah awayang. Dalam prasasti Turunhyang menyebutkan istilah aringgit, yang diartikan sebagai salah satu golongan orang-orang tertentu. Dengan demikian diketahui bahwa pada waktu itu dalam masyarakat Indonesia kuna telah ada se golongan orang yang mempunyai pekerjaan berhubungan dengan soal-soal wayang. (Wibowo;1976).

\section{Sumber Kesusastraan}

\section{a. Kakawin Ramayana}

Kakawin ini ditulis pada jaman raja Balitung. Di dalam kitab tersebut pada Sarga XXIV dapat diketahui bahwa tokoh yang berperan sebagai dalang dalam pertunjukan wayang kulit disebut Widu.

\section{b. Kakawin Arjunawiwaha}

Berita tertua tentang pertunjukan wayang kulit ditemukan dalam kakawin ini, berasal dari masa pemerintahan Airlangga dan dikarang oleh Mpu Kanwa sekitar abad XI Masehi. Di dalam kakawin ini disebutkan bahwa pada waktu itu telah dikenal pertunjukan wayang yang terbuat dari kulit, diukir dan diucapkan dengan kata-kata serta dapat membuat penonton terpengaruh jalan ceritanya. Seperti yang ditulis pada syair 9 menyebutkan :

hana nonton ringgit manangis asekel muda hidepan huwus wruh towin yan walulang inukir molah mangucap haturing wang tresneng wisaya malaha tar wihikana ri tattawanya maya sahana hananing bhawa siluman

Kurang lebih berarti: orang dapat terpengaruh cerita wayang tanpa menyadari bahwa wayang hanyalah benda yang terbuat dari kulit, di gerak-gerakkan dengan perantaraan seorang dalang. (Pane;1966, Istari;2001). 


\section{c. Kakawin Bharatayudha}

Kakawin ini berumur lebih muda daripada Kakawin Arjunawiwaha, dan dikarang oleh Mpu Sedah dan Mpu Panuluh pada jaman pemerintahan raja Jayabaya. Pada bagian muka yang dikarang oleh mpu Sedah, memperlihatkan bahwa pada waktu itu telah dikenal wayang yang menggunakan kekayon, di Jawa biasa disebut gunungan. Pada bagian belakang kakawin ini Mpu Panuluh menuliskan bahwa pertunjukan wayang tersebut diiringi dengan gamelan.

\section{d. Kitab Wrettasancaya}

Kakawin ini berasal dari jaman Kadiri akhir, diciptakan oleh Mpu Tanakung dan lebih muda daripada kakawin Bharatayudha.

Pada pupuh 93 tertulis:

$$
\text { .Lwir mawayang tahen gati nikang wukir, }
$$

Kineliran himawang anipis

Artinya: ........Gunung membayangkan kekayon layaknya,

berkeliran kabut tipis temerawang

Penyebutan kata kineliran menunjukkan bahwa pada masa itu telah dikenal pertunjukan wayang yang menggunakan kelir, diiringi gamelan dan tembang dengan menggunakan blencong/pelita.

\section{e. Kakawin Ghatotkacasraya}

Karya Mpu Panuluh dari masa pemerintahan raja Jayabaya dari kerajaan Kadiri. Dia adalah seorang pujangga pertama yang mencipta karya sastranya berdasarkan lakon yang berhubungan dengan wayang. (Timoer;1985).

\section{Sumber dari Relief Candi}

Ada beberapa candi di Jawa yang memuat relief-relief dengan melukiskan tokohtokoh pewayangan. Karena memang relief-relief itu menggambarkan kisah-kisah pewayangan, sehingga dalam penggambarannya, berbentuk pipih seperti bentuk wayang kulit.

Beberapa contoh candi di Jawa Tengah dan Jawa Timur yang berrelief wayang antara lain:

\section{a. Candi Jagu, di Kecamatan Tumpang, Malang.}

Relief yang digambarkan mengambil cerita Tantri, Kunjarakarna, Arjunawiwaha, Kresnayanan. Juga tokoh Panakawan yaitu salah satu tokoh dalam pewayangan.

\section{b. Candi Panataran, di Blitar.}

Relief menggambarkan cerita Bubuksah, Satyawan, Ramayana dan Kresnayana. 


\section{c. Candi Kedaton, di Besuki, Lumajang.}

Relief Arjunawiwaha, dan adegan dalam cerita Garudeya.

\section{d. Candi-candi di Gunung Penanggungan.}

Relief menggambarkan cerita dari adegan Ramayana, Dewa Ruci, Mintaraga dan cerita Panji.

\section{e. Candi surawana, Kediri.}

Relief yang digambarkan yaitu tentang kisah Arjunawiwaha.

\section{f. Candi Prambanan, Yogyakarta.}

Menggambarkan adegan Ramayana.

\section{g. Candi Sukuh, Karanganyar.}

Relief mengisahkan tentang cerita Bhima Bungkus atau Bhima Kumara. (Timoer;1985).

\section{$\mathbf{P}$} engertian dan Asal-usul Wayang

Arti harfiah dari wayang adalah bayangan, tetapi dalam perjalanan waktu pengertian wayang itu berubah, dan kini wayang dapat berarti: pertunjukan panggung atau teater atau dapat pula berarti aktor dan aktris. Wayang sebagai seni teater berarti pertunjukan panggung di mana sutradara ikut bermain, berbeda dari sandiwara atau film di mana sutradara tidak muncul sebagai pemain. Adapun sutradara dalam pertunjukan wayang dikenal sebagai dalang, yang peranannya dapat mendominasi pertunjukan seperti dalam wayang purwa di Jawa maupun wayang parwa di Bali. Menurut Hazeu, seorang sarjana Belanda ahli kesusastraan dan kebudayaan Jawa, mengemukakan bahwa wayang tidak berasal dari India karena istilah-istilah pokok yang menunjuk pada segi-segi teknis pertunjukannya, tidak ada yang berasal dari kata-kata bahasa Sansekerta. Hal ini memberi petunjuk bahwa kata tersebut tidak diambil dari bahasa Sansekerta, sehingga dapat dibuktikan bahwa wayang memang bukan berasal dari luar, melainkan dari budaya nenek moyang bangsa Indonesia sendiri. (Hazeu;1897).

Beberapa sarjana yang berpendapat bahwa wayang berasal dari luar Indonesia, antara lain : B.M.Geslings; mengatakan bahwa wayang berasal dari Tiongkok, dengan alasan:

a. Kata "ringgit" yang artinya sama dengan "wayang" berasal dari bahasa Cina "yinghi" yang berarti pertunjukan bayangan/bayang-bayang.

b. Rumah Indonesia yang gelap tidak memungkinkan untuk pertunjukan bayangbayang/bayangan tersebut. (Geslings; 1938). 
Tetapi pendapat ini ditentang oleh Bezemer; yang mengatakan bahwa membandingkan dua bahasa yang tidak serumpun dianggap kurang sah. Dikatakannya bahwa kata ringgit adalah kata Indonesia asli, juga tentang alasan $b /$ kegelapan rumah dalam pertunjukan bayangan/bayang-bayang dapat diatasi dengan menggunakan "blencong" (lampu minyak/pelita).

Sarjana lain yaitu Krom; mula-mula berpendapat bahwa wayang berhubungan dengan pertunjukan bayangan/bayang-bayang di India yang bernama "Chayanataka". Tetapi akhirnya Krom menyanggah pendapatnya sendiri dengan mengatakan bahwa orangorang Indonesia dahulu telah mengenal wayang yang merupakan bentuk perwujudan dari praktek pemujaan roh nenek moyang. Hal ini dapat dilihat dari cerita-cerita yang masih tersisa, misalkan cerita Watu Gunung, Darma Mikukuhan dan Batari Sri Kondur. (Pratista; 1973).

Selanjutnya ada pendapat yang mengatakan, wayang dikenal pula dengan istilah ringgit yang berasal dari dua kata, yaitu: miring dan anggit. Secara keseluruhan ringgit berarti; dicipta dalam bentuk miring. Selain kenyataan dari bentuknya yang miring, proyeksi miring juga mengandung arti "ajaran-ajaran yang belum terbuka/terus terang", diasumsikan merupakan perumpamaan yang harus kita kupas. Wayang kulit adalah pelaku yang muncul di panggung berupa boneka-boneka dua dimensi terbuat dari kulit atau belulang, ini mengandung makna bahwa yang kita lihat hanyalah kulit belaka atau bentuk wujudnya saja dan bukan isi yang terkandung di dalamnya. Untuk mendapatkan isinya, kulit itu harus kita kupas dan cerna secara lahiriah. Dalam rupa dan wujud bentuk tiap wayang terkandung watak dan jiwa, yang diisikan oleh orang yang membuat wayang tersebut dengan cara menggambarkannya. Wujud dan bentuk wayang tentu ada asal mulanya. Kita akan mengetahui bagaimana perubahan bentuk itu pada abad-abad yang lalu, bila kita membandingkan wayang jaman sekarang dengan gambaran pada relief, misalnya di candi Prambanan, candi Panataran dan wayang di Bali.

Meskipun wayang yang pada awal pertunjukannya memang hanya merupakan bayangan/bayang-bayang, tetapi kemungkinan sudah sejak lama boneka-boneka kulit itu diberi warna. Masa sekarang, wayang atau boneka-boneka kulit yang pipih itu pada umumnya dibuat dari belulang kerbau. Proses pembuatan wayang itu melalui beberapa tahap yaitu; belulang dibersihkan bulu-bulunya, dikeringkan, diperhalus dan diratakan dengan ketebalan tertentu sesuai kebutuhan, dipotong menurut polabentuk yang diinginkan barulah ditatah atau diukir. Setelah melalui proses tersebut wayang kulit diberi warna dengan memoleskan berbagai bahan pewarna yang telah dicampur dengan lem. Boneka wayang itu tidak menggambarkan manusia dengan fisik yang wajar, melainkan menggambarkan watak berbagai tokoh dalam dunia pewayangan, misalnya melukiskan watak tertentu sesuai keadaan batin tertentu pula. (Guritno;1988). 
Pendapat lain mengatakan, wayang telah ada sejak jaman neolithikum atau akhir jaman mesolithikum, yaitu sesudah 2000 tahun S.M. Pada waktu itu masih berujud prasarana bayang-bayang dalam upacara pemujaan roh nenek moyang atas dasar kepercayaan bahwa jiwa leluhur yang telah meninggal dunia masih tetap hidup dan dapat berhubungan dengan anak keturunannya, pun pula mempunyai kekuasaan untuk kebahagiaan atau sebaliknya dapat mengakibatkan suatu mala petaka bagi anak keturunannya. (Tjiptawardaja; 1990).

Pendapat-pendapat di atas ternyata tidak cukup kuat membuktikan bahwa wayang berasal dari luar Indonesia. Oleh karena itulah muncul beberapa pendapat yang mengatakan bahwa wayang adalah kesenian milik bangsa Indonesia sendiri sejak dahulu kala seperti yang telah disebutkan di atas. Hal ini diperkuat pula oleh Hazeu, bahwa wayang berasal dari pemujaan roh nenek moyang orang Jawa pada jaman kuna. Pendapat ini didukung pula oleh Stutterheim yang mengatakan bahwa upacaraupacara keagamaan jaman Indonesia kuna diwujudkan dalam bentuk wayang walaupun masih sangat sederhana. Bukti-bukti yang memperkuat dugaan tersebut, dapat dilihat dari beberapa sumber sejarah, khususnya prasasti, kesusastraan maupun relief-relief pada candi Hindu dan Buddha. Sebagaimana diketahui, bahwa masyarakat Indonesia mengkhayalkan adanya suatu kekuasaan di luar dirinya yang diperkirakan sebagai suatu tenaga misterius, dengan kemampuan daya khayal yang dimiliki itulah, manusia menciptakan suatu perwujudan yang mempersonifikasikan tenaga kekuasaan tadi. Terciptalah suatu bentuk yang dinamakan topeng dan dianggap dapat mengejawantahkan tenaga kekuasaan itu. Hanya saja topeng adalah benda mati, sehingga perlu seorang medium sebagai perantara yang dapat memanggil roh nenek moyang yang diharapkan kehadirannya melalui topeng tadi, dalam suatu upacara tertentu. Orang yang mempunyai kekuatan gaib sebagai seorang medium, kedudukan sosialnya akan naik dan dihormati. Jika orang itu meninggal, rohnya tetap dihormati dan masih dianggap mempunyai kekuasaan-kekuasaan duniawi seperti ketika dia masih hidup. Demikianlah kurang lebih sikap kepercayaan masyarakat Indonesia pada umumnya, yang akhirnya melahirkan pola pemujaan kepada nenek moyang. Pola tersebut tumbuh dengan suburnya dari generasi ke generasi berikutnya. Munculnya kerajaan Jawa-Hindu membawa perubahan pada struktur sosial budayanya, terutama dalam upacara keagamaannya, dimana topeng memerankan mahkluk supernatural. Perkembangan selanjutnya, tokoh supernatural yang diperankan, digantikan dengan tokoh dewa-dewa Hindu, kemudian berkembang menjadi tokoh-tokoh lain seperti misalnya raja-raja yang dianggap merupakan personifikasi dewa. (Timoer;1985).

Sartono mengatakan, semula topeng masih dipertahankan sebagai sarana upacara keagamaan, tetapi lambat laun sarana berupa topeng itu pun digantikan dengan boneka-boneka kulit, bentuknya pipih, di ukir-ukir, mudah digerakkan dengan tangan karena ringan. Sarana boneka kulit tersebut merupakan embrio wayang kulit sekarang ini dengan bentuk coraknya yang masih primitif. Sementara itu topeng beralih fungsi 
sebagai sarana upacara keagamaan, menjadi sarana kesenian lakon atau pertunjukan kesenian.

Adapun boneka kulit pipih itu selanjutnya menggantikan fungsi topeng yang semula sebagai sarana upacara keagamaan. Ber angsur-angsur wayang kulit ini pun berkembang dan berubah pula menjadi sarana kesenian yang sekarang dikenal dengan "kesenian pedalangan". Berlangsungnya proses peralihan fungsi ini tidak jauh berbeda dengan proses yang dialami topeng. Boneka kulit yang mungkin hanya satu dua buah untuk menggambarkan roh nenek moyang dalam upacara keagamaan makin berkembang dengan menggambarkan dewa-dewa, raja-raja dan sebagainya. Sedangkan orang yang berfungsi sebagai medium dan yang memimpin upacara keagamaan pada mulanya, beralih tugas menjadi seorang dalang dalam pertunjukan wayang kulit. (Kartodirjo;1982).

\section{$\mathbf{P}$} enutup

Melihat ke tiga jenis sumber tersebut, dapatlah diketahui bahwa pada jaman dulu telah dikenal kesenian wayang atau juga disebut ringgit. Masih belum diketahui dengan jelas adalah mengenai bentuk pertunjukannya, karena tidak disebutkan jenis wayangnya. Penyebutan tentang wayang kulit baru dikenal pada masa pemerintahan Airlangga, seperti yang terdapat dalam Kakawin Arjunawiwaha. Kemudian dari Kakawin Bharatayudha dapat diketahui bahwa pertunjukan wayang tersebut sudah diiringi dengan gamelan dan sebagainya walaupun belum selengkap seperti sekarang. Kakawin Wrettasancaya, yang masanya lebih muda, diketahui bahwa wayang pada masa itu sudah memakai kelir. Hal ini diperkuat pula dengan melihat relief wayang pada candi, meskipun pada kenyataannya candi-candi tersebut lebih muda masanya dibanding dengan kakawin Arjunawiwaha, Wrettasancaya dan Ghatokacasraya, tetapi tentunya para pemahat relief-relief tersebut mencontoh pola gambar tokoh-tokoh wayang kulit yang sudah dikenal pada masa sebelumnya.

Perihal penampilan lakon, di dalam prasasti Wukayana diketahui dengan jelas bahwa yang dipertunjukkan adalah lakon Bhima Kumara. Lakon tersebut mungkin termasuk dalam cerita ruwat, karena kata Kumara selain berarti muda juga berarti suci. Arti suci dapat juga dihubungkan dengan lakon Bhima Bungkus, yang menurut ceritanya tokoh Bhima pada waktu kelahirannya terbungkus oleh ari-ari ibunya. Ari-ari tersebut hanya dapat dipecahkan oleh dewa sehingga diartikan dengan terbukanya bungkus tersebut, Bhima dianggap suci dan kuat terhadap senjata. Cerita tentang tokoh Bhima Suci ini banyak dijumpai pada relief-relief di Gunung Penanggungan dan Candi sukuh. Relief candi yang menggambarkan cerita tersebut menunjukkan bahwa fungsi candi itu berhubungan dengan upacara ruwatan. 
Prasasti Alasantan yang ditemukan di Trowulan, menyebutkan bahwa fungsi diadakannya pertunjukan wayang berhubungan dengan upacara penetapan suatu Sima (daerah perdikan).

Jadi pertunjukan wayang ini selain berfungsi sebagai hiburan, juga mempunyai maksud sebagai pelaksanaan suatu upacara yang suci. Seperti yang disebut di dalam prasasti Penampihan dan prasasti Wukayana, pertunjukan wayang dihubungkan dengan pemujaan kepada Hyang yang pada hakekatnya sama dengan pemujaan roh nenek moyang, atau dengan kata lain wayang merupakan media penghubung antara manusia yang masih hidup dengan roh nenek moyang. Di dalam upacara penetapan sima, media ini diperlukan dengan maksud untuk menghindari hal-hal yang tidak diinginkan, yang dapat menimbulkan kegoncangan jasmani dan rohani. Cara pencegahannya dilakukan dengan jalan meruwat, yaitu mengadakan pertunjukan wayang dengan lakon Bhima Kumara atau Bhima Suci tadi.

Berdasarkan data-data tersebut dapatlah diasumsikan bahwa kesenian wayang pada waktu itu sudah mirip dengan pertunjukan wayang pada masa sekarang, khususnya wayang kulit, meskipun dulu sifatnya masih sangat sederhana. Demikianlah gambaran sepintas tentang kesenian wayang yang berkembang pada masa klasik sekitar abad IX/XIV Masehi di Jawa. 


\section{KEPUSTAKAAN}

Guritno, Pandam; 1988; Wayang, Kebudayaan Indonesia dan Pancasila; Penerbit Universitas Indonesia; Jakarta.

Geslings, B.M; 1938; Wayang op Java en Bali in het Verleden en het Heden, Amsterdam.

Hazeu, G.A.J; 1897; Bijdrage tot de Kennis van het Javaansche Toneel; E.J.Brill; Leiden.

Istari, R. (2001). Media Komunikasi Tradisional Pada Masyarakat Jawa. Berkala Arkeologi, 21(2), 48-55. https://doi.org/10.30883/jba.v21i2.840

Kartodirdjo, Sartono, A; 1982; Pemikiran dan Perkembangan Historiografi Indonesia; P.T. Gramedia; Jakarta.

Krom, N.J; 1923; Het Uode Java en Zijn Kunst; De Erven F. Behnu; Haarlem.

Marsono, Waridi Hendrosaputro (penyunting); 1999/2000; Ensiklopedi Kebudayaan Jawa; Yayasan Studi Jawa; Lembaga Studi Jawa; Yogyakarta.

Pane, Sanusi; 1960; Arjuna Wiwaha (terjemahan karya Mpu Kanwa); Balai Pustaka; Jakarta.

Pratista, Wahyu, Ki; 1973; Kupasan Wayang Purwa; Penerbit Praktis; Yogyakarta.

Sastrosuwignjo; 1973; Wayang Purwa; Sari Pers; Jakarta.

Timoer, Soenarto; 1985; Wayang Jawa Timuran Lampau dan Kini; Yayasan Ilmu Pengetahuan dan Kebudayaan Panunggalan, Lembaga Javanologi; Yogyakarta.

Tjiptawardaja, Sangkana, RA; 1990; Ruwatan Dalam Pewayangan; Lembaga Javanologi; Yayasan Ilmu Pengetahuan dan Kebudayaan Panunggalan; Balai Kajian Jarahnitra; Yogyakarta.

Wibowo, A.S; 1977; Sesdikit Catatan Tentang Wayang; 50 Tahun Lembaga Purbakala dan Peninggalan Nasional 1913-1963; Puslit Arkenas; Jakarta. 